\title{
Effect of dental bleaching after bracket bonding and debonding using three different adhesive systems
}

\author{
Lucianna de Oliveira Gomes¹, Paula Mathias², Patricia Rizzo ${ }^{3}$, Telma Martins de Araújo ${ }^{4}$, Maria Cristina Teixeira Cangussu ${ }^{5}$
}

Objective: To evaluate the influence of bonding and debonding of orthodontic brackets on dental in-home bleaching, taking into account three different adhesive systems. Methods: Forty-four bovine incisors were divided into four groups according to the primer system used for orthodontic bracket bonding. Following the debonding of orthodontic brackets, the teeth were stored in staining solution for 96 hours. Then, teeth were whitened using 10\% carbamide peroxide for two weeks at a 6-hour-a-day regime. Standardized digital photographs were taken at the following intervals: $\mathrm{T}_{0}$ (initial); $\mathrm{T}_{1}$ (after debonding); $\mathrm{T}_{2}$ (after pigmentation); $\mathrm{T}_{3}, \mathrm{~T}_{4}$ and $\mathrm{T}_{5}$ representing 1, 7, and 14 days of bleaching. Repeatability and stability tests were carried out to check the method accuracy. Images were analyzed using Adobe Photoshop 7.0 software considering $\left(\mathrm{L}^{\star} \mathrm{a} \star \mathrm{b} \mathrm{b}^{\star}\right)$ color coordinate values and a modified color difference total $\left(\Delta \mathrm{E}^{\prime}\right)$. Results: The results of this study (ANOVA and Tukey; $\mathrm{p}<0.01$ ) demonstrated that after 7 days of bleaching, experimental groups showed significantly less teeth whitening compared to the control group. However, there were no significant color differences between the groups after 14 days, according to values of lightness $\left(\mathrm{L}^{\star}\right)$. Conclusions: Regardless of the adhesive primer system applied, bonding and debonding of orthodontic brackets alters the outcome of tooth whitening in the first 7 days of bleaching, however it has no influence on the whitening of the dental structure after 14 days of in-home dental bleaching with $10 \%$ carbamide peroxide.

Keywords: Dental bleaching. Orthodontic brackets. Photography. Primer.

Objetivo: o objetivo desse estudo foi avaliar a influência da colagem e descolagem de braquetes ortodônticos no clareamento caseiro, considerando três diferentes sistemas adesivos. Métodos: quarenta e quatro incisivos bovinos foram divididos em quatro grupos, de acordo com o sistema adesivo utilizado para colagem dos braquetes. Após a descolagem dos braquetes, os dentes foram pigmentados por 96 horas e depois clareados com peróxido de carbamida a 10\% por 6 horas diárias, durante duas semanas. Foram realizadas fotografias digitais padronizadas nos tempos: $\mathrm{T}_{0}$ (inicial); $\mathrm{T}_{1}$ (após descolagem); $\mathrm{T}_{2}$ (após pigmentação); $\mathrm{T}_{3}, \mathrm{~T}_{4}$ e $\mathrm{T}_{5}$ representando 1, 7 e 14 dias de clareamento. Testes de repetitividade e de estabilidade foram realizados para avaliar a acurácia do método. As imagens foram avaliadas pelo software Adobe Photoshop 7.0, considerando os parâmetros de cor $\left(\mathrm{L}^{\star} \mathrm{a}^{\star} \mathrm{b}^{\star}\right)$ e a diferença total de cor adaptada para esse estudo $(\Delta E$ '). Resultados: os resultados do presente estudo (ANOVA e Tukey; $p<0,01$ ) demonstraram que, após uma semana de clareamento, os grupos experimentais apresentaram uma resposta mais lenta ao clareamento que o grupo controle. Contudo, após 14 dias, não houve diferença cromática significativa entre os grupos, observada pelos valores de luminosidade $\left(\mathrm{L}^{\star}\right)$. Conclusões: independentemente do sistema adesivo utilizado, a colagem e descolagem de braquetes ortodônticos altera os resultados de obtenção de cor com sete dias de avaliação. Contudo, após 14 dias não se observa nenhuma diferença de cor na estrutura dentária clareada pela técnica caseira.

Palavras-chave: Clareamento de dente. Braquetes ortodônticos. Fotografia. Adesivos.

${ }^{1} \mathrm{MSc}$ in Orthodontics. Professor, Graduate Program in Orthodontics, Federal University of Bahia (UFBa).

${ }^{2} \mathrm{PhD}$ in Orthodontics, UNICAMP. Associate Professor, UFBa.

${ }^{3} \mathrm{MSc}$ in Dentistry, UFBa.

${ }^{4} \mathrm{PhD}$ in Orthodontics. Full Professor, Graduate Program in Orthodontics, UFBa.

${ }^{5}$ Associate Professor, Department of Social and Pediatric Dentistry, UFBa.

" The author reports no commercial, proprietary or financial interest in the products or companies described in this article.
How to cite this article: Gomes LO, Mathias P, Rizzo P, Araújo TM, Cangussu MCT. Effect of dental bleaching after bracket bonding and debonding using three different adhesive systems. Dental Press J Orthod. 2013 Mar-Apr;18(2):61-8.

Submitted: October 20, 2010

Revised and accepted: September 15, 2011

Contact address: Lucianna de Oliveira Gomes Faculdade de Odontologia, Universidade Federal da Bahia Rua Araújo Pinho, $62-7^{\circ}$ andar - Salvador/BA, Brazil CEP: 40.110-150 -E-mail: lurufino@uol.com.br 


\section{INTRODUCTION}

Patients frequently seek cosmetic solutions after orthodontic treatments including changes in tooth color, notably when stains are observed on tooth surface after the removal of orthodontic brackets. Usually, such stains result from pigments in the materials applied in the tooth/bracket interface, since orthodontic devices prevent good hygiene and favor the deposit of chromogenic agents in the interfaces between tooth enamel and orthodontic device which may lead to color alteration on the dental surface. ${ }^{1}$

However, after debonding of orthodontic brackets, residual adhesive (resin tags) remain on teeth, for the bonding process takes place as a result of the micromechanical retention, due to the presence of resin components that infiltrate about $11.8 \mu \mathrm{m}$ to $18.9 \mu \mathrm{m}$ into the dental structure, sometimes reaching up to $100 \mu \mathrm{m}$ into the tooth. ${ }^{2,3}$

Once resin tags have infiltrated the enamel - and some may remain intact even if the enamel's surface layer is removed, ${ }^{4}$ they could obstruct the movement of whitening agents within this substrate hence influencing the result of dental bleaching. ${ }^{5}$ In addition, since composites are not whitened, as teeth are, ${ }^{6}$ their presence could lead to chromatic alterations and prevent the acquisition of a homogenous color on dental surface in the end of the bleaching process.

In face of the scarce literature on dental bleaching after debonding of orthodontic brackets, as well as on the influence of resin tags on dental surface final color, it is necessary to assess occasional differences on the color of teeth whitened after bonding and debonding of orthodontic brackets taking into consideration the different adhesive primer systems.

The first research hypothesis is that the adhesive resin system that remains on tooth enamel after debonding of orthodontic brackets interferes with the achievement of a homogenous surface color. The second research hypothesis is that different adhesive primer systems interfere differently with the outcome of dental bleaching.

\section{MATERIAL AND METHODS}

Forty-four incisors previously kept in a $0.1 \%$ timol solution were assessed colorimetrically and fifteen were used for the method repeatability test and color stability test. The teeth had their roots cut off with a double-face diamond disc (\# 7020, KG Sorensen, Barueri, SP, Brazil) under refrigeration and in low rotation. Dental pulps were removed and crowns were brushed using Robinson brushes and pumice-based toothpaste and water in low rotation. The central region - the most flat surface - on the buccal side of each tooth was outlined and dental crowns were included in transparent self-cured acrylic resin blocks (JET, Artigos Odontológicos Clássico Ltda, São Paulo, SP, Brazil). The specimens were randomly divided into five groups, as shown in Table 1.

The bracket placed on the flattened surface was that of a maxillary lateral incisor ref. 1030209 (Morelli, São Paulo, SP, Brazil), manipulated with the aid of bracket bonding tool (Morelli). The specimens of all groups were placed in the positioning device, their exposed enamels etched with 37\% phosphoric acid for 1 minute and underwent bracket-bonding procedures according the instructions provided by the manufacturers of the different adhesive primer systems applied. Before debracketing, the specimens were stored in distilled water for 24 hours at $37^{\circ} \mathrm{C} .^{7,8}$

Debonding was carried out mechanically with a straight plier How (Unitek), following the technique proposed by Zachrisson. ${ }^{9}$ The remaining composite

Table 1 - Description of experimental groups according to surface treatment, composite resin, whitening procedure and sample size.

\begin{tabular}{|c|c|c|c|c|}
\hline GROUPS & SURFACE TREATMENT & COMPOSITE RESIN & BLEACHING AGENT & TOTAL TEETH (n) \\
\hline Color stability and Repeatability (R) & ----------- & ------ & ------- & 15 \\
\hline Control (C) & ------------ & ------ & $10 \%$ carbamide peroxide & 11 \\
\hline Self-Etching Primer (SEP) & Transbond plus self-etching primer & Transbond XT & $10 \%$ carbamide peroxide & 11 \\
\hline Transbond Primer (TP) & Phosph. ac. $37 \%+$ Transbond Primer & Transbond XT & $10 \%$ carbamide peroxide & 11 \\
\hline Concise Resin (CR) & Phosph. ac. $37 \%+$ Concise resin & Concise & $10 \%$ carbamide peroxide & 11 \\
\hline
\end{tabular}


was removed with a multilaminated bur (K282K Komet-Brasseler, Lemgo, Germany) in low rotation. The total removal of composite from enamel was verified in a stereoscope microscope (25x).

After bracket debonding, the specimens of groups C, SEP, TP and CR were submerged in a container with aqueous solution containing $250 \mathrm{ml}$ of black tea, $250 \mathrm{ml}$ of coffee, $250 \mathrm{ml}$ of red wine, $250 \mathrm{ml}$ of tobacco solution, $250 \mathrm{ml}$ of coca-cola and $250 \mathrm{ml}$ of artificial saliva, at $37^{\circ} \mathrm{C}$ for 96 hours.

After pigmentation, specimens were subjected to the at-home whitening technique, using 10\% carbamide peroxide (7.82 pH) (Whiteness Perfect 10\% - FGM, Joinville, SC, Brazil).

During bleaching, a standardized $0.2 \mathrm{ml}$ whitening substance was applied over the exposed tooth surface, which was kept there for 6 hours a day, during 2 consecutive weeks. The specimens remained under 100\% relative humidity at $37^{\circ} \mathrm{C}$ throughout the experiment..$^{10}$

Specimens were photographed using positioning devices, developed with the goal of assessing the enamel color always at the same spot at the different assessment intervals, at the following time points: $\mathrm{T}_{0}=$ initial, before bracket bonding; $\mathrm{T}_{1}=$ after debonding and surface polishing; $\mathrm{T}_{2}=$ after pigmentation; $\mathrm{T}_{3}=$ after the first day of bleaching; $\mathrm{T}_{4}=$ after the first week of bleaching; $T_{5}=$ after two weeks of bleaching. Specimens in the control group were polished and photographed again at $\mathrm{T}_{1}$ in compliance with the method applied for experimental groups.

\section{Determining method reliability: Repeatability test}

Before starting the experiment, a repeatability test of the photograph shooting and the resulting color measurements was performed on fifteen specimens to ensure the reliability of the method applied. The repeatability test consisted of an assessment of tooth color variation across three photography sessions.

\section{Color stability test on teeth stored in distilled water}

This test consisted in the observation of possible color alterations on teeth stored in distilled water at $37^{\circ} \mathrm{C}$ across the experimental period. Fifteen specimens had their photographic images assessed at $\mathrm{T}_{0}$ (initial) and $\mathrm{T}_{5}$ (final) intervals. This so-called group $\mathrm{R}$ did not undergo any kind of treatment on their exposed enamel surfaces.

\section{Color measurement of sample}

Measurements of $\mathrm{L}^{\star}, \mathrm{a}^{\star}, \mathrm{b}^{\star}$ color dimensions were carried out at the aforementioned time periods $\left(\mathrm{T}_{0}\right.$ to $\mathrm{T}_{5}$ ) on all experimental specimens by using the histogram function of the Adobe Photoshop 7.0 software.

The study adopted the CIELAB color system in which colors are defined according to three dimensions: $L^{\star}$ (lightness), $a^{\star}$ and $b^{\star}$ (redness/greenness and yellowness/blueness). ${ }^{11}$ The numeric values of $\mathrm{L}^{\star}$, $a^{\star}, b^{\star}$ obtained from colorimeters and spectrophotometers vary from 0 to 160 . In this study, $L^{\star}, a^{\star}, b^{\star}$ dimensions vary from 0 to 255 because the color assessment relied upon the computer-based readings of digital photographs that are obtained in the RGB color space, with 256 different hues. Therefore, we needed to adjust the numeric value, which suggests clinical significance (DE) (Table 2). So we agreed to name the color difference calculated in this study DE', to prevent wrong comparisons based on DE calculated from $\mathrm{L}^{\star} \mathrm{a}^{\star} \mathrm{b} \star$ color parameters obtained with colorimeters.

\section{Data assessment}

The values of $L^{\star} a^{\star} b^{\star}$ resulting from the colorimetric assessment of photographs were statistically evaluated by the MINITAB package.

The ANOVA test (analysis of variance) was performed for repeated data, to check for the statistically significant differences at the intervals and among all groups in the study. Once a positive result was observed for ANOVA, we applied the Tukey parametric statistics to determine the minimum significant differences among groups at each interval and among different intervals within each group, at the 1\% significance level.

Table 2 - $\triangle E$ CIELAB color variation (0 - 160 scale) and $\Delta E^{\prime}$ RGB color variation (0 - 255 scale).

CIE color space: L $(0$ to 100$)$; a $(-80$ to +80$) ; b(-80$ to +80$)$ $\Delta \mathrm{E}=\left[(100)^{2}+(160)^{2}+(160)^{2}\right]^{1 / 2}$

$\Delta \mathrm{E}=247.39$

RGB color space: L ( 0 to 255$) ;$ a ( 0 to 255$)$; b ( 0 to 255$)$

$\Delta \mathrm{E}^{\prime}=\left[(256)^{2}+(256)^{2}+(256)^{2}\right]^{1 / 2}$

$\Delta \mathrm{E}^{\prime}=443.40$ 


\section{RESULTS}

\section{Color stability and repeatability test}

The degree of repeatability of the sample was found to be highly reliable, as confirmed by the Analysis of Variance (ANOVA), since no significant difference $(\mathrm{p}>0.01)$ was observed among the values of $L^{\star}(F=0.58 / p=0.57), a^{\star}(F=0.71 / p=0.8)$ and $b^{\star}(F=0.3 / p=0.74)$ for each specimen at the three intervals.

With regards to the color stability test on specimens kept in distilled water, the difference in the values of $\mathrm{L}^{\star}, \mathrm{a}^{\star}, \mathrm{b}^{\star}$ at time points $\mathrm{T}_{0}$ and $\mathrm{T}_{5}$ did not result in statistically significant differences throughout the sample storage period (Table 3).

\section{Colorimetric assessment results Value of $L^{*}$}

The measurement of luminosity values $L^{\star}$, at time points $\mathrm{T}_{0}$ to $\mathrm{T}_{5}$, for Control (C), Transbond Primer (TP), Self-Etching Primer (SEP) and Concise Resin (CR) groups are displayed on Table 4 and Figure 1.

Considering differences in lightness among specimens across intervals, it was noted that after bonding and debonding of orthodontic brackets $\left(T_{1}\right)$ teeth in groups SEP and CR displayed statistically significant differences $(p<0.01)$ when compared to teeth in group $\mathrm{C}$ (Table 4 and Fig 1). The value of $L^{\star}$ decreased in all groups (C, TP, SEP and CR) between $\mathrm{T}_{1}$ and $\mathrm{T}_{2}$, thus demonstrating the darkening of the sample after the pigmentation of the specimens (Table 4 and Fig 1).

A significant increase of $\mathrm{L}^{\star}$ between intervals $\mathrm{T}_{0}$ $\mathrm{T}_{5}$ and intervals $\mathrm{T}_{2}-\mathrm{T}_{5}\left(\Delta \mathrm{L}^{\prime}\right)$ was observed (Table 4$)$. Between $\mathrm{T}_{2}-\mathrm{T}_{3}$ the difference in $\mathrm{L}^{\star}$ was not significant for the CR group, indicating a delay in the whitening effect over this group compared to the others. From $\mathrm{T}_{3}$ to $T_{4}$ the variation in $L^{\star}$ values was statistically significant for the Control group only. The difference in the measurement of $L^{\star}$ between $T_{4}$ and $T_{5}$ was significant $(\mathrm{p}<0.01)$ for all groups. At $\mathrm{T}_{4}$ and $\mathrm{T}_{5}$ the differences among the four groups were not statistically significant, hence demonstrating the groups' homogenous behavior after two weeks of whitening (Fig 1).

\section{Value of $\Delta E^{\prime}$}

The value of DE', which expresses the total color difference, was determined from the measurement of $L^{\star}, a^{\star}$ and $b^{\star}$. There was an increase in the value
Table 3 - Descriptive values of $L^{*} a^{*} b^{*}$ color dimensions related to Group $\mathrm{R}$.

\begin{tabular}{ccccc}
\hline Time points & & L* $^{*}$ & $\mathbf{a}^{*}$ & $\mathbf{b}^{*}$ \\
$T_{0}$ & $\bar{X}$ & 159.31 & 128.22 & 139.11 \\
& S.D. & 3.27 & 0.427 & 0.480 \\
$T_{5}$ & $\bar{X}$ & 160.17 & 128.41 & 139.91 \\
& S.D. & 3.20 & 0.433 & 0.583 \\
\hline
\end{tabular}

$\bar{X}=$ mean, S.D. $=$ standard deviation $p<0.01$.

Table 4 - Mean, standard deviation and the value of $L^{*}$ comparing control and experimental groups at time points $T_{0}, T_{1}, T_{2}, T_{3}, T_{4}$ and $T_{5}$

\begin{tabular}{|c|c|c|c|c|c|}
\hline \multicolumn{2}{|c|}{ Time points } & C group & SEP group & TP group & CR group \\
\hline \multirow{2}{*}{$\mathrm{T}_{0}$} & $\bar{x}$ & $169.11^{\mathrm{ABa}}$ & $170.15^{\mathrm{Aa}}$ & $168.97^{\mathrm{Aba}}$ & $169.12^{\mathrm{Aa}}$ \\
\hline & S.D. & 2.75 & 3.04 & 3.01 & 4.07 \\
\hline \multirow{2}{*}{$T_{1}$} & $\bar{x}$ & $170.71 \mathrm{Aa}$ & $175.72^{\mathrm{Bb}}$ & $173.95^{\mathrm{Cab}}$ & $176.18^{\mathrm{BDb}}$ \\
\hline & S.D. & 3.25 & 3.00 & 3.39 & 3.70 \\
\hline \multirow{2}{*}{$T_{2}$} & $\bar{X}$ & 159.80 Сa & $165.61^{\mathrm{Cb}}$ & $165.09^{A b}$ & $163.02^{\mathrm{Cab}}$ \\
\hline & S.D. & 3.72 & 2.31 & 3.23 & 4.07 \\
\hline \multirow{2}{*}{$\mathrm{T}_{3}$} & $\bar{x}$ & $165.01 \mathrm{Ba}$ & $170.51^{\mathrm{Ab}}$ & $169.81^{\mathrm{Bb}}$ & 167.62 ACab \\
\hline & S.D. & 3.61 & 2.19 & 2.92 & 4.26 \\
\hline \multirow{2}{*}{$\mathrm{T}_{4}$} & $\bar{x}$ & $171.07 \mathrm{Aa}$ & $171.38 \mathrm{Aa}$ & $171.86^{\text {BCa }}$ & $171.67 \mathrm{ABa}$ \\
\hline & S.D. & 2.34 & 2.55 & 3.01 & 3.80 \\
\hline \multirow{2}{*}{$\mathrm{T}_{5}$} & $\bar{x}$ & 180.12 Еa & $181.67 \mathrm{Da}$ & $180.89 \mathrm{Da}$ & $181.16^{\mathrm{Da}}$ \\
\hline & S.D. & 2.95 & 3.20 & 3.44 & 4.06 \\
\hline
\end{tabular}

$\bar{X}=$ mean, S.D. $=$ standard deviation $p<0.01$.

$A, B, C, D, E$ show differences within the same groups at the different intervals (columns) a,b show differences among different groups at the same intervals (rows).

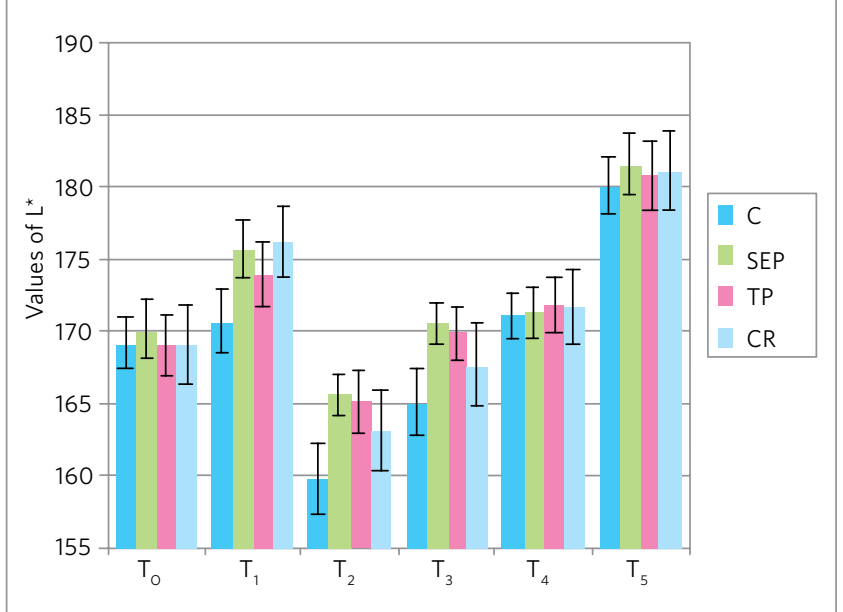

Figure 1 - Graphic representation of the mean values of $L^{*}$ and their respective confidence intervals, considering Control and Experimental groups at the different time intervals $(p<0.01)$. 
of DE' from $\mathrm{T}_{0}$ to $\mathrm{T}_{1}$ between group $\mathrm{C}$ and experimental groups SEP, TP and CR indicating that the processes of bonding and debonding of orthodontic brackets altered the total color of teeth. Such alteration was greater in group CR, which demonstrated a higher value of DE' at $\mathrm{T}_{1}$ (Table 5 ) when compared against group $\mathrm{C}$.

From $\mathrm{T}_{0}$ to $\mathrm{T}_{1}$ groups SEP and CR displayed significant color difference after the debonding of orthodontic brackets (Table 5). From $\mathrm{T}_{1}$ to $\mathrm{T}_{2}$ all groups showed significant color alterations. Groups $\mathrm{CR}$ and $\mathrm{C}$ displayed the highest values of DE' from $\mathrm{T}_{1}$ to $\mathrm{T}_{2}$ (Table 5).

After one day of whitening no significant color difference was detected in any group from $T_{2}$ to $T_{3}$. However, after one week of whitening $\left(\mathrm{T}_{2}-\mathrm{T}_{4}\right)$ significant color difference was displayed in all groups; control group displayed the greatest difference (Table 5).

Upon assessing the difference among groups at a fixed interval, no significant difference was observed among the groups at $\mathrm{T}_{0}$. Noticeable color difference between $\mathrm{C}$ and SEP, and between $\mathrm{C}$ and $\mathrm{CR}$ was observed after the debonding of brackets $\left(\mathrm{T}_{1}\right)$. After one and two weeks of whitening there was no significant color difference among the groups (Table 6).

\section{DISCUSSION}

The use of specific colorimetric devices allows a faster and more consistent color assessment than visual assessments alone. ${ }^{12}$ The color assessment method applied in this study was the computer-based evaluation of photographic images, supported by Gerlach, Barker, Sagel ${ }^{13}$ Gerlach, Gibb, Sagel $;{ }^{14}$ Bentley et al. ${ }^{11}$ These authors state that an ideal color assessment method

\begin{tabular}{ccccc} 
Table 5 - Descriptive values of $\Delta E^{\prime}$ at the different evaluated time points. \\
\hline Intervals & C group & SEP group & TP group & CR group \\
\hline$T_{0}-T_{1}$ & 1.69 & 5.63 & 5.03 & 7.12 \\
$T_{0}-T_{2}$ & 9.47 & 4.63 & 4.12 & 6.32 \\
\hline$T_{1}-T_{2}$ & 11.07 & 10.20 & 9.03 & 13.33 \\
\hline$T_{2}-T_{3}$ & 5.35 & 5.03 & 4.96 & 4.78 \\
\hline$T_{2}-T_{4}$ & 12.12 & 6.90 & 8.19 & 9.60 \\
\hline$T_{2}-T_{5}$ & 21.40 & 17.18 & 17.20 & 19.21 \\
\hline$T_{3}-T_{4}$ & 6.90 & 2.90 & 3.79 & 4.99 \\
\hline$T_{3}-T_{5}$ & 16.08 & 12.24 & 12.29 & 14.45 \\
\hline$T_{4}-T_{5}$ & 9.34 & 10.56 & 9.30 & 9.74 \\
\hline$T_{0}-T_{5}$ & 12.12 & 12.65 & 13.09 & 12.92 \\
\hline$T_{1}$ & & &
\end{tabular}

$p<0.01$.
Table 6 - Descriptive values of $\Delta \mathrm{E}^{\prime}$ according to the experimental and control groups.

\begin{tabular}{ccccccc}
\hline Groups & $\mathrm{T}_{0}$ & $\mathrm{~T}_{1}$ & $\mathrm{~T}_{2}$ & $\mathrm{~T}_{\mathbf{3}}$ & $\mathrm{T}_{4}$ & $\mathrm{~T}_{5}$ \\
\hline C - SEP & 1.22 & 5.67 & 5.86 & 5.54 & 0.71 & 1.62 \\
C - TP & 0.60 & 3.88 & 5.32 & 4.83 & 0.84 & 0.81 \\
\hline C - CR & 0.17 & 6.10 & 3.25 & 2.64 & 0.74 & 1.08 \\
SEP - TP & 1.20 & 1.79 & 0.78 & 0.73 & 0.61 & 0.81 \\
SEP - CR & 1.21 & 0.86 & 2.61 & 2.91 & 0.37 & 0.56 \\
TP - CR & 0.65 & 2.35 & 2.10 & 2.20 & 0.25 & 0.29 \\
\hline
\end{tabular}

$p<0.01$

must be reliable, user-friendly and capable of allowing for a retrospective evaluation of results. In addition, using relatively low-cost and widely available equipment like a digital camera is extremely interesting.

The CIELAB color variation system is widely used in dentistry to measure the pigmentation of composites, ${ }^{15,16}$ assess the color of dental ceramics ${ }^{12}$ and teeth, ${ }^{17}$ the chromatic alteration after dental bleaching ${ }^{5,11,13,14}$ and after debonding of orthodontic accessories. ${ }^{18}$ The advantage of the CIELAB color system is that color differences can be expressed in units (DE), which can be related to the visual perception and the clinical significance. ${ }^{19}$ In the literature, the color value difference (DE) which can be clinically noticeable, i.e., which suggests clinical significance, is controversial and shows variations from 2.2 to $4.4 .{ }^{17}$ However, Dozic et $\mathrm{al}^{20}$ found noticeable color differences under clinical conditions only when DE was greater than 3.0 units. As a result, the calculation of DE' will be based on a 3.0-unit DE. Therefore, we applied a common rule-of-three equation to calculate the color value difference (DE') which determines the clinical significance in this study. Because the variation of the mean value of DE is 0 to 247.39 and DE' is 0 to 443.40 , when DE equals 3.0 units,,$^{20} \mathrm{DE}$ ' will be 5.37 units. Thus, the clinical significance in this study was established for values of DE'> 5.37 units.

Bonding and debonding of orthodontic brackets cause the color on dental surface to change as verified by the increase in the value of $L^{\star}$, statistically significant between $\mathrm{T}_{0}$ and $\mathrm{T}_{1}$ for groups SEP, TP and CR, and also clinically significant $(\mathrm{p}<0.01)$ for SEP and $\mathrm{CR}\left(\mathrm{DE}^{\prime}=5.63\right.$ and 7.12 respectively) (Tables 4 and 5). 
The presence of resin tags in the enamel, filling the "pores" created by the acidic condition of the enam$\mathrm{el}$, indicates that it is the driver of those changes. ${ }^{23}$ The difference among the experimental groups is probably due to the different adhesive systems that were utilized..$^{23}$ The increase in the value of $L^{\star}$ in the Concise Resin group was also found in the Osório ${ }^{23}$ experiment. The presence of resins within the enamel porosity may have modified a luminous reflection from the dental surface.

Hintz, Bradley and Eliades ${ }^{5}$ state that there are three possible variations in bracket debonding procedures that can be responsible for the differences observed among the experimental surfaces: Quantity, quality and depth of resin tags, meaning the change in the morphology of the enamel as a result of the bonding and debonding procedures, and the amount of enamel lost during debonding. Considering these three possibilities, changes observed in the specimens of this study are probably due to the different resin tags left inside the dental substrate because the differences are observed among the experimental groups and between those and the control group. The other aforementioned variables act individually on the specimens, regardless of the group, possibly causing high intragroup variance, which was not observed in this study (Tables 4 and 5).

The decrease in the value of $L^{\star}$ from $T_{1}$ to $T_{2}$ did not occur homogeneously in all groups $(\mathrm{C}, \mathrm{TP}, \mathrm{SEP}$ and CR) (Table 4 and Fig 1). Pigment absorption was greater in groups $\mathrm{C}$ and $\mathrm{CR}$. In case of the control group it was due to lack of tags on the dental surface, which favors the diffusion of bleaching agent's molecules ${ }^{5}$. In case of group CR it was due to the improved color stability of light-cured composites as compared to chemically cured composites (Fig 1). The presence of amines and benzoyl peroxide in chemically cured composite products contributes to a greater pigmentation when compared to light-cured ones. ${ }^{24,25}$

After one day of whitening we detected a statistically significant increased value of $L^{\star}$ for groups $\mathrm{C}$, SEP and TP. This whitening observed in some groups after six hours of exposure to carbamide peroxide was possibly the result of the pigment deposited on the surface of the specimens. Authors report color alteration on dental surface related to the use of $10 \%$ carbamide peroxide, observed clinically after one week of application. ${ }^{26,27}$ Therefore, the whitening observed at this interval $\left(\mathrm{T}_{3}\right)$ was more related to the superficial removal of the just-deposited than to the bleaching effect itself.

After one week of whitening only the Control group displayed a significant increase in the value of $\mathrm{L}^{\star}$, indicating a delayed whitening in the experimental groups as compared to Control at $\mathrm{T}_{3}$ and $\mathrm{T}_{4}$. These results are according to those of Hintz, Bradley and Eliades ${ }^{5}$ demonstrating the absence of initial response to whitening in the experimental group. These authors report that the experimental group did not respond to whitening for the first two weeks. After two weeks, however, the whitening in the experimental group was faster than that in the control group.

At $\mathrm{T}_{5}$, after 14 days of whitening, all groups (C, SEP, TP and CR) displayed a significant increase $(p<0.01)$ in the value of $L^{\star}$, which confirms the specimens lighter appearance. It is notable that the teeth became lighter than their initial color (DE' from $\mathrm{T}_{0}$ to $\mathrm{T}_{5}$ ) (Table 5) before pigmentation, confirming the effectiveness of the bleaching agent.

In the end of the whitening process, at $T_{5}$, the values of DE' among the groups do not demonstrate any clinically significant color difference (Table 6), hence showing that the bonding and debonding of orthodontic brackets did not interfere on the whitening of the specimens. Hintz, Bradley and Eliades ${ }^{5}$ found similar data by the end of the whitening process, according to which either control or experimental groups displayed significant color alterations. Therefore, the first research hypothesis was rejected since the presence of resin tags did not altered the final result of the at-home whitening process carried out for 14 days, thus demonstrating that the quantity of resin remaining within the dental enamel was not enough to prevent the diffusion of the whitening agent inside the dental structure.

Nevertheless, more time in the application of the whitening agent is required to grant the same degree of color modification between the control group and the experimental groups as indicated by existing differences in the value of $\mathrm{L}^{\star}$ between $\mathrm{T}_{3}$ and $\mathrm{T}_{4}$, in control and experimental groups (Table 4). In the current study, due to the bonding and debonding of orthodontic accessories as well as the pigmentation procedures, control and experimental groups began whitening with 
different values of $L^{\star}$. The control groups displayed a darker color than the experimental groups, with differences reaching up to 6 units of $L^{\star}$ between $C$ and $S E$ at $\mathrm{T}_{2}$ (Table 4). Therefore, although the color differences among groups $\mathrm{C}, \mathrm{SEP}, \mathrm{TP}$ and $\mathrm{CR}$ at $\mathrm{T}_{4}$ (after 7 days of whitening) are not significant $(\mathrm{p}>0.01)$ (Fig 1), only the control group displayed a statistically significant color change $\left(T_{3}\right.$ and $\left.T_{4}\right)$. This finding indicates that the control group changed color more rapidly than the experimental groups, when exposed to bleaching procedures (Table 4 and Fig 1). These findings match those of Hintz, Bradley and Eliades, ${ }^{5}$ which state that, initially, tags do make it more difficult for the whitening agent to penetrate the tooth but with a longer exposure to the whitening substance the final result of the whitening process is not compromised.

In the end, the lack of difference among the experimental groups will lead to the rejection of the second research hypothesis, which suggested different group behaviors due to the role played by their specific resin remaining. However, during the experiment, significant color differences were verified for the different adhesive primer systems applied, especially after the debonding of orthodontic brackets and before dental whitening $\left(\mathrm{T}_{2}\right.$ and $\left.\mathrm{T}_{3}\right)$.

Although CIELAB coordinates values are important for an objective color assessment, clinical significance (DE) plays a fundamental role in the de- termination of what is actually perceived under the social and clinical stand points. Consequently, taking this clinical significance into consideration, the results of this study demonstrate that the bonding and debonding of orthodontic brackets will not prevent the achievement of homogenous dental whitening. Nevertheless, a differentiated clinical protocol should be observed to allow an increased treatment time for the whitening of teeth that have endured bonding and debonding of orthodontic brackets. Despite the similar behavior of human and bovine teeth during staining and bleaching ${ }^{28}$ procedures, further studies using human dental substrates and assessing different intervals are required.

\section{CONCLUSION}

In light of the findings in this study, it could be concluded that:

1. After 14 days of at-home dental whitening there was no statistically significant color difference among the groups that were subjected to bonding and debonding of orthodontic brackets and the control group.

2. Regardless of the adhesive primer system applied, dental whitening was uniformly achieved in the three experimental groups, without any statistically significant color differences among the groups in the end of dental whitening process. 
1. Feinman RAB, Madray G, Yarborough D. Chemical, optical and physiologic mechanisms of bleaching products: a review. Pract Periodontics Aesthet Dent. 1991;3(2):32-6

2. Diedrich $P$. Enamel alterations from bracket bonding and debonding: a study with the scanning electron microscope. Am J Orthod. 1981;79(5):500-22.

3. Menezes LFS, Chevitarese O. Sealant and resin viscosity and their influence on formation of resin tags. Angle Orthod. 1995;64(5):383-8.

4. Zachrisson BU, Artun J. Enamel surface appearance after various debonding techniques. Am J Orthod. 1979;75:121-37.

5. Hintz JK, Bradley TG, Eliades T. Enamel colour changes following whitening with 10 per cent carbamide peroxide: a comparison of orthodontically-bonded/ debonded and untreated teeth. Eur J Orthod. 2001;23(4):411-5.

6. Villalta P, Lu H, Okte Z, Garcia-Godoy F, Powers JM. Effects of staining and bleaching on color change of dental composite resin. J Prosthet Dent. 2006;95(2):137-42

7. Eliades GC, Vougiouklakis GJ, Caputo AA. Degree of double bond conversion in light-cured composites. Dent Mater. 1987;3(1):19-25.

8. Chamda RA, Stein E. Time-related bond strengths of light-cured and chemically cured bonding systems: an in vitro study. Am J Orthod Dentofacial Orthop. 1996;110(4):378-82.

9. Zachrisson BU. Bonding in orthodontics. In: Graber TM, Vanarsdall RL. Orthodontics: current principles and techniques. $3^{\text {rd }}$ ed. St. Louis: Mosby; 2000. 1040 p

10. Alves EA, Alves FKA, Campos EJ, Mathias P. Susceptibility to caries-like lesions after dental bleaching with different techniques. Quintessence Int. 2007;38(7):e404-9.

11. Bentley C, Leonard RH, Nelson CF, Bentley SA. Quantitation of vital bleaching by computer analysis of photographic images. J Am Dental Assoc. 1999;130(6):809-16.

12. Seghi RR, Johnston WM, O'Brien WJ. Performance assessment of colorimetric devices on dental porcelains. J Dent Res. 1989;68(12):1755-9.

13. Gerlach RW, Barker ML, Sagel PA. Objective and subjective whitening response of two self-directed bleaching systems. Am J Dent. 2000;21:22-8.

14. Gerlach RW, Gibb RD, Sagel PA. A randomized clinical trial comparing a novel $5.3 \%$ hydrogen peroxide bleaching strip to $10 \%, 15 \%$ and $20 \%$ carbamide peroxide tray-based bleaching systems. Compend Contin Educ Dent. 2002;15:7-12.
15. Scotti R, Mascellani SC, Fornit F. The in vitro color stability of acrylic resins for provisional restorations. Int J Prosthodont. 1997;10(2):164-8

16. Dietschi D, Campanile G, Holz J, Meyer, JM. Comparison of the color stability of ten new generation composites: an in vitro study. Dent Mater. 1994;10(6):353-62

17. Dozic A, Kleverlaan CJ, Aartman IHA, Feilzer AJ. Relation in color of three regions of vital human incisors. Dent Mater. 2004;20(9):832-8.

18. Eliades T, Kakaboura A, Eliades G, Bradley TG. Comparison of enamel colour changes associated with orthodontic bonding using two different adhesives. Eur J Orthod. 2001;23(1):85-90

19. O'Brien WJ, Hemmendinger H, Boenke KM, Linger JB, Groh, CL. Color distribution of three regions of extracted human teeth. Dent Mater. 1997;13(3):179-85

20. Dozic A, Kleverlaan CJ, Aartman IHA, Feilzer AJ. Relation in color among maxillary incisors and canines. Dent Mater. 2005;21(3):187-91.

21. Ruyter IE, Nilner K, Moller B. Color stability of dental composite resin materials for crown and bridge veneers. Dent Mater. 1987;3(5):246-51.

22. Johnston WN, Kao EC. Assessment of appearance match by visual observation and clinical colorimetry. J Dent Res. 1998;68(5):819-22.

23. Osório LB. Alterações cromáticas e micromorfológicas do esmalte submetido ao procedimento de clareamento pós-descolagem [thesis]. Rio de Janeiro (RJ): Federal University of Rio de Janeiro; 2000

24. Asmussen E. Factors affecting the color stability of restorative resins. Acta Odontol Scand. 1983;41(1):11-8.

25. Tyas MJ. Colour stability of composite resins: a clinical comparison. Aust Dent J. 1992;37(2):88-90.

26. Kihn PW, Barnes DM, Romberg E, Peterson BS. A clinical evaluation of 10 percent vs. 15 percent carbamide peroxide tooth-whitening agents. J Am Dent Assoc. 2000;131(10):1478-84.

27. Jones HA, Diaz-Arnold MA, Vargas AM, Cobb SD. Colorimetric assessment of laser and home bleaching techniques. J Esthet Dent. 1999;11(2):87-94.

28. Attia ML, Aguiar FHB, Mathias P, Ambrosano GMB, Fontes CM, Liproni PC. The effect of coffee solution on tooth color during home bleaching applications. Am J Dent. 2009:22(3):175-9. 